\title{
Target value of mean arterial pressure in patients undergoing continuous renal replacement therapy due to acute kidney injury
}

Yaerim Kim', Donghwan Yun², Soie Kwon², Kyubok Jin ${ }^{1}$, Seungyeup Han ${ }^{1}$, Dong Ki Kim², Kook-Hwan Oh², Kwon Wook Joo ${ }^{2}$, Yon Su Kim², Sejoong Kim ${ }^{2,3^{*}}$ and Seung Seok Han ${ }^{2 *}$ (D)

\begin{abstract}
Background: Although patients undergoing continuous renal replacement therapy (CRRT) due to acute kidney injury (AKI) frequently have instability in mean arterial pressure (MAP), no consensus exists on the target value of MAP related to high mortality after CRRT.

Methods: A total of 2,292 patients who underwent CRRT due to AKI in three referral hospitals were retrospectively reviewed. The MAPs were divided into tertiles, and the $3^{\text {rd }}$ tertile group served as a reference in the analyses. The major outcome was all-cause mortality during the intensive care unit period. The odds ratio (OR) of mortality was calculated using logistic regression after adjustment for multiple covariates. The nonlinear relationship regression model was applied to determine the threshold value of MAP related to increasing mortality.

Results: The mean value of MAP was $80.7 \pm 17.3 \mathrm{mmHg}$ at the time of CRRT initiation. The median intensive care unit stay was 5 days (interquartile range, 2-12 days), and during this time, 1,227 (55.5\%) patients died. The $1^{\text {st }}$ tertile group of MAP showed an elevated risk of mortality compared with the $3^{\text {rd }}$ tertile group (adjusted OR, 1.28 [1.031.60]; $P=0.029$ ). In the nonlinear regression analysis, the threshold value of MAP was calculated as $82.7 \mathrm{mmHg}$. Patients with MAP $<82.7 \mathrm{mmHg}$ had a higher mortality rate than those with $\geq 82.7 \mathrm{mmHg}$ (adjusted OR, 1.21 $[1.01-1.45] ; P=0.037)$.
\end{abstract}

Conclusions: Low MAP at CRRT initiation is associated with a high risk of mortality, particularly when it is $<82.7$ $\mathrm{mmHg}$. This value may be used for risk classification and as a potential therapeutic target.

Keywords: Acute kidney injury, Continuous renal replacement therapy, Mean arterial pressure, Mortality

\section{Background}

Preventing hypotension is a crucial issue in critically ill patients because of its relationship with high mortality and other poor outcomes [1, 2]. Accordingly, the guidelines for septic patients requiring vasopressors suggest initially

\footnotetext{
*Correspondence: sejoong@snubh.org; hansway80@gmail.com ${ }^{2}$ Department of Internal Medicine, Seoul National University College of Medicine, 103 Daehakro, Jongno-gu, Seoul 03080, Korea Full list of author information is available at the end of the article
}

maintaining mean arterial pressure $(\mathrm{MAP})>65 \mathrm{mmHg}$, followed by monitoring via multiple hemodynamic parameters to an endpoint of tissue perfusion [3]. Furthermore, this target value should be individualized to the pertinent circumstances or patient characteristics.

Continuous renal replacement therapy (CRRT) is a rescue therapy for patients displaying both unstable vital signs and severe acute kidney injury (AKI). Hypotension after initiating CRRT is a frequent occurrence [4] and

(c) The Author(s). 2021 Open Access This article is licensed under a Creative Commons Attribution 4.0 International License, which permits use, sharing, adaptation, distribution and reproduction in any medium or format, as long as you give appropriate credit to the original author(s) and the source, provide a link to the Creative Commons licence, and indicate if changes were made. The images or other third party material in this article are included in the article's Creative Commons licence, unless indicated otherwise in a credit line to the material. If material is not included in the article's Creative Commons licence and your intended use is not permitted by statutory regulation or exceeds the permitted use, you will need to obtain permission directly from the copyright holder. To view a copy of this licence, visit http://creativecommons.org/licenses/by/4.0/ The Creative Commons Public Domain Dedication waiver (http://creativecommons.org/publicdomain/zero/1.0/) applies to the data made available in this article, unless otherwise stated in a credit line to the data. 
can aggravate CRRT-related mortality, reaching 50\% [5, 6]. Because patients requiring CRRT have AKI as well as other critical conditions, their target value of MAP may be different from that of other critically ill patient subsets or recommended MAP values. An elegant multicenter study including patients with septic shock suggests that a MAP of $65-70 \mathrm{mmHg}$ is enough to guarantee survival compared with $80-85 \mathrm{mmHg}$ [7]; however, only $40 \%$ of those patients had AKI, and there was no information regarding CRRT. The target blood pressure values in hemodialysis patients are suggested as $<140$ $\mathrm{mmHg}$ and $<90 \mathrm{mmHg}$ for systolic and diastolic blood pressures, respectively (i.e., MAP is calculated as 106.7
$\mathrm{mmHg}$ [ [8], but this value could not be applied in cases of CRRT because the patient condition is much different from that of conventional hemodialysis patients. Collectively, there are no current guidelines or evidence for the target value of MAP in patients initiating CRRT due to AKI. Therefore, we addressed this issue using a multicenter cohort of patients with AKI requiring CRRT.

\section{Methods}

\section{Study populations}

A total of 2,292 patients who were $\geq 18$ years old and had AKI requiring CRRT were consecutively reviewed from January 2010 to December 2019. Of these, patients with

Table 1 Baseline characteristics according to the mean arterial pressure

\begin{tabular}{|c|c|c|c|c|c|}
\hline Variables & Total $(n=2,211)$ & $1^{\text {st }}$ tertile $(n=746)$ & $2^{\text {nd }}$ tertile $(n=724)$ & $3^{\text {rd }}$ tertile $(n=741)$ & $P$-value \\
\hline Age (year) & $65.0 \pm 15.2$ & $66.4 \pm 14.7^{\ddagger}$ & $64.9 \pm 15.6$ & $63.6 \pm 15.1$ & 0.001 \\
\hline Male (\%) & 60.8 & 58.6 & 60.4 & 63.6 & 0.137 \\
\hline Body weight (kg) & $60.9 \pm 12.7$ & $60.5 \pm 12.5^{*}$ & $60.3 \pm 12.8^{*}$ & $61.9 \pm 12.8$ & 0.034 \\
\hline Mechanical ventilator (\%) & 79.1 & 80.0 & 79.0 & 78.3 & 0.705 \\
\hline Vasopressors (\%) & 69.0 & 70.1 & 69.5 & 67.5 & 0.520 \\
\hline Diabetes mellitus (\%) & 27.1 & 34.8 & 26.7 & 26.7 & 0.802 \\
\hline Hypertension (\%) & 26.5 & 28.2 & 23.3 & 27.9 & 0.063 \\
\hline Ischemic heart disease (\%) & 11.0 & 11.8 & 10.6 & 10.5 & 0.687 \\
\hline COPD (\%) & 3.7 & 2.9 & 4.4 & 3.6 & 0.324 \\
\hline Cancer (\%) & 34.3 & 34.7 & 35.6 & 32.5 & 0.434 \\
\hline Mean arterial pressure $(\mathrm{mmHg})$ & $80.7 \pm 17.3$ & $63.3 \pm 8.3^{\ddagger}$ & $79.3 \pm 3.9^{\ddagger}$ & $99.7 \pm 11.9$ & $<0.001$ \\
\hline Heart rate (/min) & $104.7 \pm 25.9$ & $103.4 \pm 26.4$ & $104.9 \pm 24.8$ & $105.7 \pm 26.4$ & 0.235 \\
\hline Respiratory rate (/min) & $23.5 \pm 7.8$ & $23.4 \pm 7.9$ & $23.3 \pm 7.8$ & $23.7 \pm 7.7$ & 0.646 \\
\hline Body temperature $\left({ }^{\circ} \mathrm{C}\right)$ & $36.5 \pm 1.5$ & $36.4 \pm 1.9$ & $36.5 \pm 1.3$ & $36.5 \pm 1.2$ & 0.093 \\
\hline $\mathrm{FiO} 2$ & $0.6[0.4-0.9]$ & $0.6[0.4-1.0]$ & $0.6[0.4-0.9]$ & $0.6[0.4-0.9]$ & 0.172 \\
\hline $\mathrm{PaO} 2$ & $92.0[71.0-128.0]$ & $89.5[70.0-124.0]$ & $96.5[73.0-133.0]$ & $90.0[69.8-128.3]$ & 0.311 \\
\hline $\mathrm{AaDO}_{2}$ & 253.7 [122.4-469.0] & 284.6 [132.9-499.9] & $241.6[119.7-454.1]$ & $243.3[119.2-471.1]$ & 0.161 \\
\hline \multicolumn{6}{|l|}{ Laboratory findings } \\
\hline $\mathrm{pH}$ & $7.3 \pm 0.2$ & $7.3 \pm 0.1^{\dagger}$ & $7.3 \pm 0.1$ & $7.3 \pm 0.1$ & 0.003 \\
\hline White blood cells ( $\left.\times 10^{3} / \mathrm{uL}\right)$ & $11.9[6.7-18.7]$ & $11.6[6.5-19.5]$ & $11.9[7.0-18.6]$ & $12.2[6.7-18.3]$ & 0.609 \\
\hline Hemoglobin (g/dL) & $9.8 \pm 2.1$ & $9.7 \pm 2.0^{*}$ & $9.7 \pm 2.2^{*}$ & $10.0 \pm 2.1$ & 0.019 \\
\hline Platelet $\left(\times 10^{3} / \mathrm{uL}\right)$ & $102.0[59.0-166.0]$ & $98.0[59.0-157.0]$ & $103.0[58.0-171.0]$ & $105.0[58.0-171.0]$ & 0.906 \\
\hline Sodium (mmol/L) & $138.5 \pm 7.6$ & $138.8 \pm 8.0$ & $138.1 \pm 7.5$ & $138.5 \pm 7.2$ & 0.154 \\
\hline Potassium (mmol/L) & $4.4 \pm 1.0$ & $4.4 \pm 1.0$ & $4.3 \pm 0.9$ & $4.4 \pm 1.0$ & 0.313 \\
\hline BUN (mg/dL) & $44.0[29.0-65.0]$ & $41.0[27.0-64.0]$ & $45.5[30.0-66.0]$ & $45.0[30.0-65.0]$ & 0.243 \\
\hline Creatinine $(\mathrm{mg} / \mathrm{dL})$ & $2.4[1.6-3.5]$ & $2.2[1.6-3.3]^{*}$ & $2.4[1.6-3.6]$ & $2.5[1.6-3.7]$ & 0.031 \\
\hline Albumin (g/dL) & $2.8 \pm 0.6$ & $2.7 \pm 0.6^{\ddagger}$ & $2.8 \pm 0.6^{*}$ & $2.9 \pm 0.6$ & $<0.001$ \\
\hline Bilirubin (mg/dL) & $1.8[0.8-4.1]$ & $1.9[0.9-4.1]$ & $1.9[0.8-4.5]$ & $1.6[0.8-3.7]$ & 0.935 \\
\hline CRRT dose $(\mathrm{ml} / \mathrm{kg} / \mathrm{hr})$ & $40.0[35.0-42.0]$ & $40.0[35.0-43.8]$ & $40.0[35.0-44.0]$ & $40.0[35.0-40.0]$ & 0.402 \\
\hline APACHE $\|$ & $22.4 \pm 9.7$ & $24.6 \pm 9.8^{\ddagger}$ & $21.1 \pm 9.5$ & $21.3 \pm 9.5$ & $<0.001$ \\
\hline
\end{tabular}

All continuous variables were represented with median [interquartile range]

COPD Chronic obstructive pulmonary disease, MAP mean arterial pressure, $A a D O_{2}$ alveolar-arterial oxygen difference, $B U N$ blood urea nitrogen, $C R R T$ continuous renal replacement therapy, APACHE Acute Physiology and Chronic Health Evaluation

${ }^{*} P<0.05 ;{ }^{\dagger} P<0.01 ;{ }^{\ddagger} P<0.001$, compared with the $3^{\text {rd }}$ tertile 
Table 2 Risk of intensive care unit-mortality according to the tertiles of mean arterial pressure

\begin{tabular}{|c|c|c|c|c|c|c|c|c|}
\hline \multirow[b]{2}{*}{ Groups } & \multicolumn{2}{|l|}{ Model 1} & \multicolumn{2}{|l|}{ Model 2} & \multicolumn{2}{|l|}{ Model 3} & \multicolumn{2}{|l|}{ Model 4} \\
\hline & OR (95\% CI) & $P$-value & OR (95\% Cl) & $P$-value & OR $(95 \% \mathrm{Cl})$ & $P$-value & OR $(95 \% \mathrm{Cl})$ & $P$-value \\
\hline $3^{\text {rd }}$ tertile & 1 (Reference) & & 1 (Reference) & & 1 (Reference) & & 1 (Reference) & \\
\hline $2^{\text {nd }}$ tertile & $1.245(1.014-1.529)$ & 0.037 & $1.253(1.020-1.540)$ & 0.031 & $1.210(0.974-1.504)$ & 0.086 & $1.183(0.949-1.475)$ & 0.136 \\
\hline $1^{\text {st }}$ tertile & $1.577(1.283-1.937)$ & $<0.001$ & $1.596(1.298-1.963)$ & $<0.001$ & $1.342(1.076-1.673)$ & 0.009 & $1.290(1.031-1.614)$ & 0.026 \\
\hline
\end{tabular}

Model 1: Not adjusted

Model 2: Adjusted for age and sex

Model 3: Model 2 plus, body weight, body temperature, using inotropics, support by mechanical ventilator, serum pH, serum hemoglobin, serum albumin, and APACHE II score

Model 4: Model 3 plus variables with $P<0.1$ in univariate analysis

$\mathrm{Cl}$ confidence interval, $\mathrm{OR}$ odds ratio

underlying end-stage renal disease before starting CRRT $(n=81)$ were excluded. Accordingly, 2,211 patients were analyzed in the study (Figure S1). Under the terms of ethics approval, the requirement for informed consent was waived.

\section{Study variables and outcome}

The data at the time of CRRT initiation were obtained via electronic medical records. Clinical data such as age, sex, body weight, application of mechanical ventilation, use of vasopressors and comorbidities including diabetes mellitus, hypertension, ischemic heart disease, chronic obstructive pulmonary disease, and cancer were reviewed. The vital signs, such as the mean arterial pressure, heart rate, respiratory rate, body temperature, and alveolar-arterial oxygen difference, were measured. Blood laboratory data, such as $\mathrm{pH}$, white blood cell count, hemoglobin, platelets, sodium, potassium, blood urea nitrogen, creatinine, albumin, and bilirubin, were measured. There were no missing variables. The Acute Physiologic Assessment and Chronic Health Evaluation (APACHE) II score was calculated based on the method presented in the original study [9]. The primary outcome was all-cause mortality during the stay in the intensive care unit (ICU).

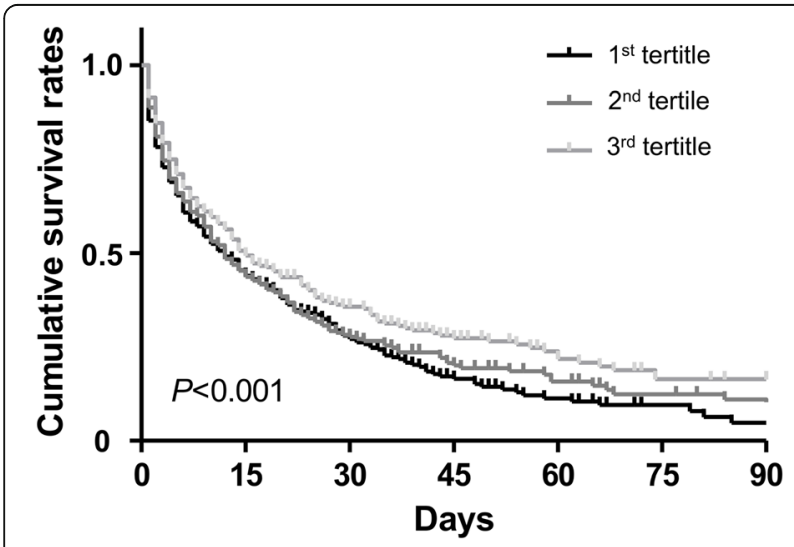

Fig. 1 Sunvival curves according to the tertiles of mean arterial pressure

\section{Statistical analysis}

Statistical analyses were performed using SPSS (version 23.0; IBM Corp., Armonk, NY, USA), SAS (version 9.4; SAS Institute Inc., Cary, NC, USA), and R (version 3.5.3; The Comprehensive R Archive Network: http://cran.rproject.org) software. Categorical and continuous variables were expressed as proportions and means \pm standard deviations if they had a normal distribution and as medians with interquartile ranges if they were not normally distributed. The chi-square test was used for comparison of categorical variables (Fisher's exact test if applicable), and Student's t-test or the Mann-Whitney $U$ test was used for continuous variables with or without a normal distribution, respectively. Initially, patients were divided according to the tertiles of MAP, and the risk of ICU mortality was calculated using the logistic regression model with stepwise multivariate adjusting methods. The variance inflation factor was less than 1.5 for all variables, which indicated there was no

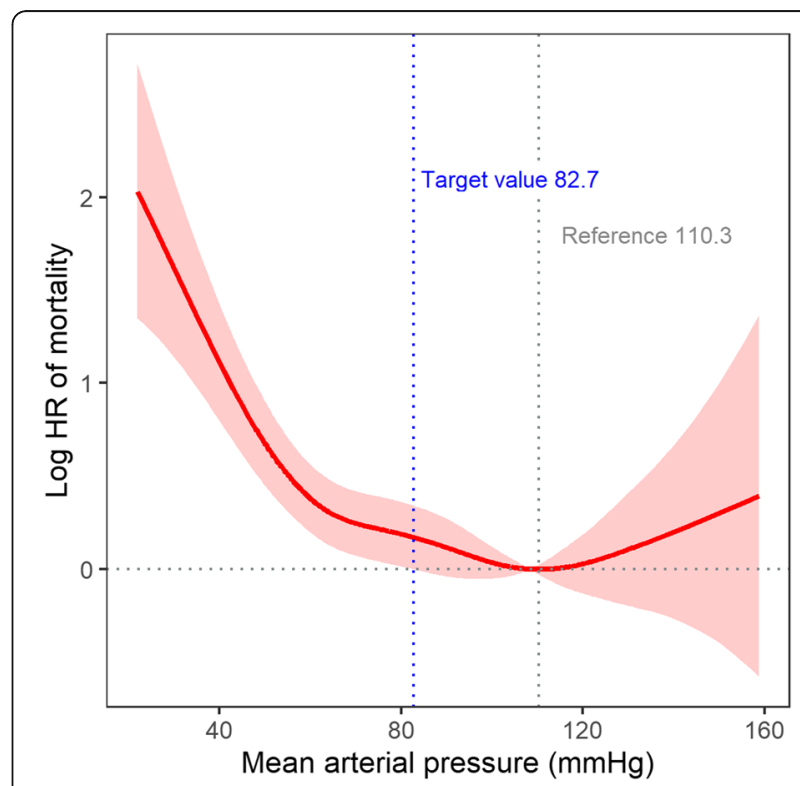

Fig. 2 Nonlinear relationship between mean arterial pressure and mortality. The area indicates $95 \%$ confidence intervals. HR, hazard ratio 
Table 3 Risk of intensive care unit-mortality in patients with low mean arterial pressure

\begin{tabular}{|c|c|c|c|c|c|c|c|c|}
\hline \multirow[b]{2}{*}{ Groups } & \multicolumn{2}{|l|}{ Model 1} & \multicolumn{2}{|l|}{ Model 2} & \multicolumn{2}{|l|}{ Model 3} & \multicolumn{2}{|l|}{ Model 4} \\
\hline & OR $(95 \% \mathrm{Cl})$ & $P$-value & OR (95\% Cl) & $P$-value & OR $(95 \% \mathrm{Cl})$ & $P$-value & OR $(95 \% \mathrm{Cl})$ & $P$-value \\
\hline High MAP ( $\geq 82.7 \mathrm{mmHg}$ ) & 1 (Reference) & & 1 (Reference) & & 1 (Reference) & & 1 (Reference) & \\
\hline Low MAP (< 82.7 mmHg) & $1.344(1.134-1.593)$ & 0.001 & $1.354(1.141-1.605)$ & 0.001 & $1.219(1.017-1.462)$ & 0.032 & $1.222(1.015-1.471)$ & 0.034 \\
\hline
\end{tabular}

collinearity. Additive generalized models with penalized splines (package: $m g c v$ ) were used to analyze the relationship between MAP and ICU mortality. A target value was indicated when the lower limit of $95 \%$ confidence intervals of ORs was $\geq 0$ compared with a reference MAP. Kaplan-Meier survival curves were drawn and compared using the log rank test. $P$ values $<0.05$ were defined as significant when they were set to twosided.

\section{Results}

\section{Study subjects}

The baseline characteristics of the patients are shown in Table 1. The mean age of the patients was $65.0 \pm 15.2$ years, and $60.8 \%$ were male. The CRRT mode was continuous veno-venous hemodiafiltration. The median duration of CRRT was 3 days (IQR, 1-7 days). The mean value of MAP at the time of CRRT initiation was $80.7 \pm$ $17.3 \mathrm{mmHg}$. When the patients were divided according to the tertiles of MAP, the lowest tertile group displayed older age, lower values of arterial $\mathrm{pH}$, serum hemoglobin, creatinine, and albumin, and higher scores for APACHE II than the other tertiles (Table 1).

\section{Relationship between MAP and mortality}

The association between MAP levels and ICU mortality was evaluated after categorizing patients into the tertiles of MAP. A total of 1,227 patients (55.5\%) died during the ICU period. The prevalence of death was $61.1 \%$, $55.4 \%$, and $49.9 \%$ from the $1^{\text {st }}$ to the $3^{\text {rd }}$ tertiles. In the univariate analysis, the $1^{\text {st }}$ tertile group had a $58 \%$ increased risk for mortality compared with the $3^{\text {rd }}$ tertile group (Table 2). Even after several variables were adjusted in a stepwise fashion, the $1^{\text {st }}$ tertile group had a higher risk of mortality than the $3^{\text {rd }}$ tertile group (Table 2). The Kaplan-Meier survival curves also supported these results (Fig. 1).

\section{Target value of MAP related to high mortality}

The nonlinear relationship between MAP and the risk of ICU mortality demonstrated that there seemed to be a target value of MAP related to increasing mortality (Fig. 2). To identify the target value, we used the penalized spline curve with a reference of which log hazard ratio (HR) and the $95 \%$ confidence interval were set to zero, and a referential MAP was defined when the minimal log HR was between $80 \mathrm{mmHg}$ and $100 \mathrm{mmHg}$. When MAP was 82.7 $\mathrm{mmHg}, \log \mathrm{HR}$ started to increase, and its lower 95\% confidence interval was $>0$. Accordingly, $82.7 \mathrm{mmHg}$ appeared to be the target value of MAP for ICU mortality.

After dividing patients into high $(\geq 82.7 \mathrm{mmHg})$ and low $(<82.7 \mathrm{mmHg}$ ) MAP groups, the low MAP group had different characteristics from the high MAP group based on age; sex; body weight; heart rate; serum values of hemoglobin, creatinine, and albumin; and APACHE II score (Table S1). Patients with low MAP had an additional $34.4 \%$ risk of ICU mortality compared with those with high MAP (Table 3). After several variables were adjusted in a stepwise fashion, the low MAP group was associated with high ICU mortality (Table 3). The Kaplan-Meier survival curves also supported these results (Fig. 3). Figure 4 demonstrates that the high risk of ICU mortality depending on the target value of MAP remained consistent irrespective of age, sex, diabetes mellitus, and other variables.

\section{Discussion}

Prevention of hypotension and maintaining proper tissue perfusion is the treatment goal for critically ill patients.

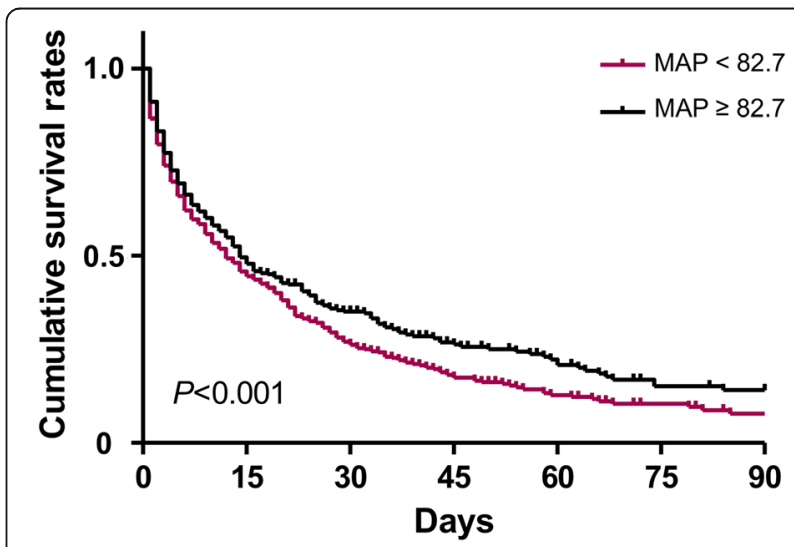

Fig. 3 Survival during the stay of the intensive care unit according to the high $(\geq 82.7 \mathrm{mmHg})$ and low $(<82.7 \mathrm{mmHg})$ mean arterial pressures (MAPs) 


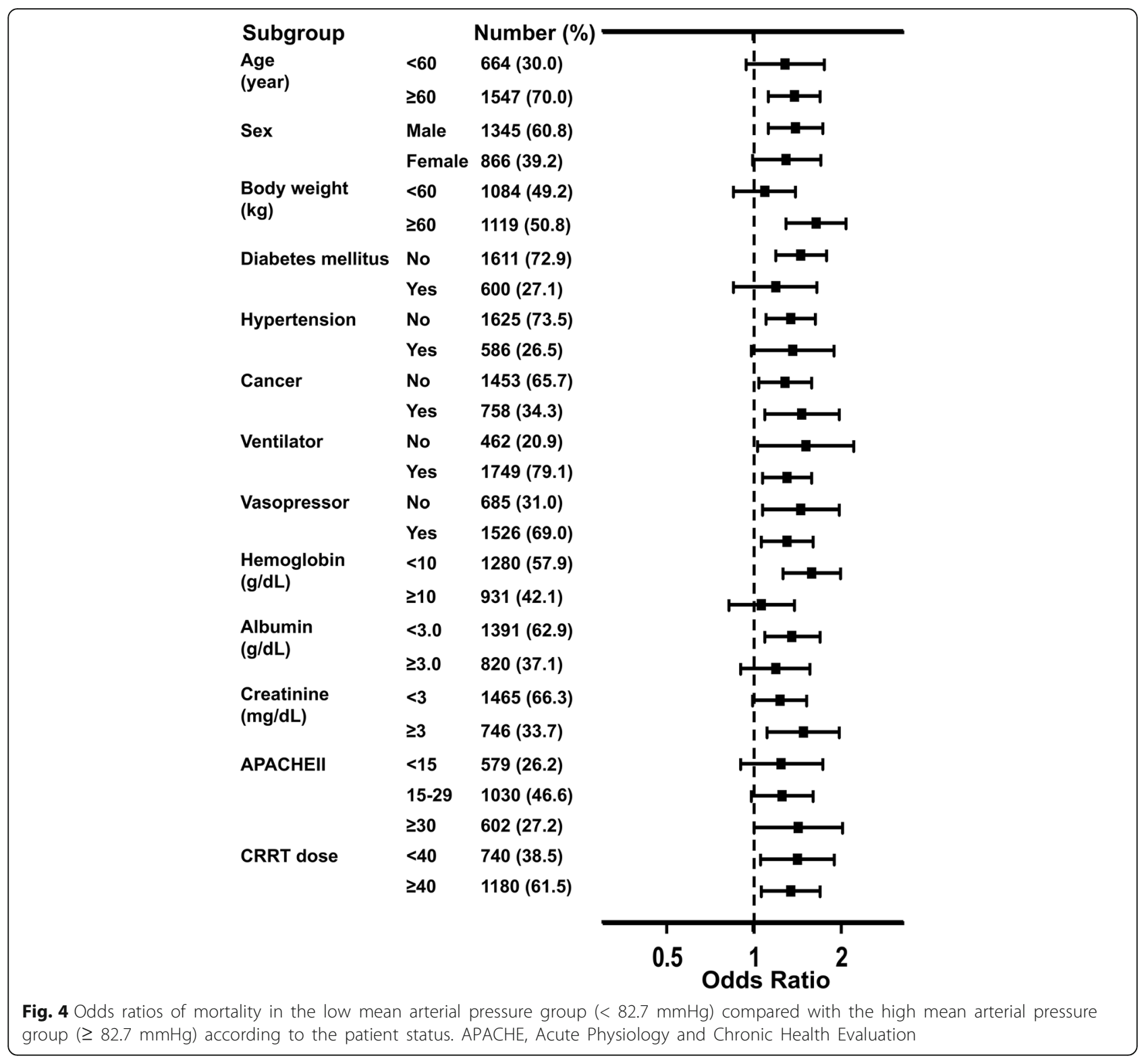

Alarming a target value of MAP should facilitate the management of these patients, but this issue has not been evaluated in patients requiring CRRT despite their high mortality rates. The present study identified that baseline MAP at the time of starting CRRT was associated with the mortality risk. When a nonlinear relationship was applied, the potential target value of MAP was calculated as $82.7 \mathrm{mmHg}$. Accordingly, a warning for MAP values above this target may be needed at the time of initiating CRRT.

Among the patients requiring intensive care, a substantial proportion of patients suffered from AKI and may have needed the support of CRRT. AKI adds a significant burden to critically ill patients and ultimately leads to a poor outcome and high mortality. Among several risk factors in this patient subset, an abnormal blood pressure range has been included in the scoring system of outcome prediction [9-11]. Although CRRT provides gentle modification of electrolyte, acid-base, and fluid imbalance with hemodynamic tolerance compared with intermittent hemodialysis, early exposure to hypotension during CRRT may be associated with high mortality [6]. In addition to tissue hypoxia, low blood pressures affect the adequacy of CRRT by clotting in the circuit system. This event finally propagates hypotension as a vicious cycle. Accordingly, increasing the blood pressures over the target value may be needed before starting CRRT as a preventive management.

MAP levels of less than 60 or $70 \mathrm{mmHg}$ were associated with mortality in patients with septic shock [12, 
13]. Based on these results, the Surviving Sepsis Guideline suggests that the cutoff value of MAP in septic patients is $65 \mathrm{mmHg}$ [14], which was supported by a cohort study wherein MAP less than $65 \mathrm{mmHg}$ with a longer duration of exposure significantly increased the mortality of patients with septic shock [15]. A large randomized trial showed that a higher target for MAP of 80 to $85 \mathrm{mmHg}$ did not differ from 65 to $70 \mathrm{mmHg}$ regarding the risk of mortality in patients with septic shock [7]. Another randomized trial, in which a higher target for MAP of 75 to $80 \mathrm{mmHg}$ did not provide a survival benefit compared with 60 to $65 \mathrm{mmHg}$ in patients with shock regardless of the cause, supports these results [16]. The target value may be individualized according to the patient characteristics and comorbidities. For example, higher targets are needed in patients with atherosclerosis and/or previous hypertension than in young patients without cardiovascular comorbidity [14]. However, this issue has not been resolved in patients with AKI requiring CRRT until the present study. The present target value of $82.7 \mathrm{mmHg}$ is higher than the $65 \mathrm{mmHg}$ recommended by the guidelines [7, 12-17]. Patients with AKI requiring CRRT are in poor medical condition with impairment of the autoregulatory system $[18,19]$, which requires higher blood circulation than patients without severe AKI. These results do not justify the use of excessive inotropics in patients with low MAP because of their side effects. The issue on the inotropics use should be solved in the future study with randomized, controlled design.

Although the present study had strengths, such as a large number of CRRT patients from multi-centers, there were certain limitations to be discussed. The study could not determine causality between MAP and mortality because of the nature of its retrospective design. The important confounders, such as heart function, cause of AKI, severity of AKI at the time of CRRT initiation, and the detailed information of CRRT prescription, were not considered in the analyses. These unidentified factors may have interacted with the preset relationships. The study results were not validated in an independent cohort. The cause of death could not be obtained in the present dataset.

Patients with AKI requiring CRRT are at risk of high mortality, and thus, prediction and alarming of their outcomes throughout monitoring of MAP are critical issues. The present study identified that low MAP at CRRT initiation was associated with high mortality, particularly when it was less than $82.7 \mathrm{mmHg}$. This target value could serve as a risk classification and a potential therapeutic target in patients with AKI requiring CRRT. In addition, the present results provide the basis of future studies regarding other outcomes such as renal outcome after CRRT.

\section{Supplementary Information}

The online version contains supplementary material available at https://doi. org/10.1186/s12882-020-02227-4.

Additional file 1: Table S1. Baseline characteristics in the high $(\geq 82.7$ $\mathrm{mmHg})$ and low $(<82.7 \mathrm{mmHg}$ ) mean arterial pressure groups. Figure S1. Flow diagram of the study populations.

\section{Acknowledgments \\ None. \\ Disclosure \\ None. \\ Authors' contributions \\ YK designed the study, collected the data, and drafted the manuscript. DY analyzed the results. SK collected data. KJ, SH, DKK, KHO, KWJ, and YSK revised manuscript and reviewed the manuscript. SK and SSH conceived the study, analyzed the results, interpreted the data, and reviewed the manuscript. All of the authors read and approved the final manuscript.}

\section{Funding}

This research was supported by grant No. 2019R1A2C1085411 from the National Research Foundation.

\section{Availability of data and materials}

The datasets used and/or analyzed during the current study available from the corresponding author on reasonable request.

\section{Ethics approval and consent to participate}

The study was approved by the institutional review boards of Seoul National University Hospital (H-1812-069-993), Seoul National University Bundang Hospital (B-1901/519-410), and Keimyung University Dongsan Medical Center (2020-03-009) and conducted in accordance with the Declaration of Helsinki. All of the clinical information was extracted by retrospective review, and informed consent was waived under the approval.

Consent for publication

Not Applicable.

\section{Competing interests}

There was no conflict of interest in all authors participated in this research.

\section{Author details}

${ }^{1}$ Department of Internal Medicine, Keimyung University School of Medicine, Daegu, Korea. ${ }^{2}$ Department of Internal Medicine, Seoul National University College of Medicine, 103 Daehakro, Jongno-gu, Seoul 03080, Korea.

${ }^{3}$ Department of Internal Medicine, Seoul National University Bundang Hospital, 82, Gumi-ro 173beon-gil, Bundang-gu, Seongnam-si, Gyeonggi-do 13620, Korea.

Received: 10 September 2020 Accepted: 25 December 2020

Published online: 09 January 2021

\section{References}

1. Maheshwari K, Nathanson BH, Munson SH, Khangulov V, Stevens M, Badani $\mathrm{H}$, Khanna AK, Sessler DI. The relationship between ICU hypotension and inhospital mortality and morbidity in septic patients. Intensive Care Med. 2018;44(6):857-67.

2. Yapps B, Shin S, Bighamian R, Thorsen J, Arsenault C, Quraishi SA, Hahn JO, Reisner AT. Hypotension in ICU patients receiving vasopressor therapy. Sci Rep. 2017;7(1):8551.

3. Rhodes A, Evans LE, Alhazzani W, Levy MM, Antonelli M, Ferrer R, Kumar A, Sevransky JE, Sprung CL, Nunnally ME, et al. Surviving sepsis campaign: international guidelines for management of sepsis and septic shock: 2016. Crit Care Med. 2017:45(3):486-552.

4. Akhoundi A, Singh B, Vela M, Chaudhary S, Monaghan M, Wilson GA, Dillon JJ, Cartin-Ceba R, Lieske JC, Gajic O, et al. Incidence of adverse events during continuous renal replacement therapy. Blood Purif. 2015;39(4):333-9. 
5. Iwagami M, Yasunaga H, Noiri E, Horiguchi H, Fushimi K, Matsubara T, Yahagi N, Nangaku M, Doi K. Current state of continuous renal replacement therapy for acute kidney injury in Japanese intensive care units in 2011: analysis of a national administrative database. Nephrol Dial Transplant. 2015; 30(6):988-95.

6. Shawwa K, Kompotiatis P, Jentzer JC, Wiley BM, Williams AW, Dillon JJ, Albright RC, Kashani KB. Hypotension within one-hour from starting CRRT is associated with in-hospital mortality. J Crit Care. 2019;54:7-13.

7. Asfar P, Meziani F, Hamel JF, Grelon F, Megarbane B, Anguel N, Mira JP, Dequin PF, Gergaud S, Weiss N, et al. High versus low blood-pressure target in patients with septic shock. N Engl J Med. 2014;370(17):1583-93.

8. Jindal K, Chan CT, Deziel C, Hirsch D, Soroka SD, Tonelli M, Culleton BF. Hemodialysis clinical practice guidelines for the Canadian Society of Nephrology. J Am Soc Nephrol. 2006;17(3 Suppl 1):S1-27.

9. Knaus WA, Draper EA, Wagner DP, Zimmerman JE. APACHE II: a severity of disease classification system. Crit Care Med. 1985;13(10):818-29.

10. de Mendonca A, Vincent IL, Suter PM, Moreno R, Dearden NM, Antonelli M, Takala J, Sprung C, Cantraine F. Acute renal failure in the ICU: risk factors and outcome evaluated by the SOFA score. Intensive Care Med. 2000;26(7): 915-21.

11. Kim Y, Park N, Kim J, Kim DK, Chin HJ, Na KY, Joo KW, Kim YS, Kim S, Han SS Development of a new mortality scoring system for acute kidney injury with continuous renal replacement therapy. Nephrology (Carlton). 2019; 24(12):1233-40

12. Varpula M, Tallgren M, Saukkonen K, Voipio-Pulkki LM, Pettilä V. Hemodynamic variables related to outcome in septic shock. Intensive Care Med. 2005;31(8):1066-71.

13. Dünser MW, Takala J, Ulmer H, Mayr VD, Luckner G, Jochberger S, Daudel F, Lepper P, Hasibeder WR, Jakob SM. Arterial blood pressure during early sepsis and outcome. Intensive Care Med. 2009;35(7):1225-33.

14. Dellinger RP, Levy MM, Rhodes A, Annane D, Gerlach H, Opal SM, Sevransky JE, Sprung $C L$, Douglas IS, Jaeschke $R$, et al. Surviving sepsis campaign: international guidelines for management of severe sepsis and septic shock: 2012. Crit Care Med. 2013;41(2):580-637.

15. Vincent JL, Nielsen ND, Shapiro NI, Gerbasi ME, Grossman A, Doroff R, Zeng F, Young PJ, Russell JA. Mean arterial pressure and mortality in patients with distributive shock: a retrospective analysis of the MIMIC-III database. Ann Intensive Care. 2018;8(1):107.

16. Lamontagne F, Meade MO, Hébert PC, Asfar P, Lauzier F, Seely AJE, Day AG, Mehta S, Muscedere J, Bagshaw SM, et al. Higher versus lower blood pressure targets for vasopressor therapy in shock: a multicentre pilot randomized controlled trial. Intensive Care Med. 2016;42(4):542-50.

17. Leone M, Asfar P, Radermacher P, Vincent JL, Martin C. Optimizing mean arterial pressure in septic shock: a critical reappraisal of the literature. Crit Care. 2015;19:101.

18. Vaara ST, Pettila V, Kaukonen KM, Bendel S, Korhonen AM, Bellomo R, Reinikainen M. The attributable mortality of acute kidney injury: a sequentially matched analysis*. Crit Care Med. 2014:42(4):878-85.

19. Kolhe NV, Muirhead AW, Wilkes SR, Fluck RJ, Taal MW. National trends in acute kidney injury requiring dialysis in England between 1998 and 2013. Kidney Int. 2015;88(5):1161-9.

\section{Publisher's Note}

Springer Nature remains neutral with regard to jurisdictional claims in published maps and institutional affiliations.

Ready to submit your research? Choose BMC and benefit from:

- fast, convenient online submission

- thorough peer review by experienced researchers in your field

- rapid publication on acceptance

- support for research data, including large and complex data types

- gold Open Access which fosters wider collaboration and increased citations

- maximum visibility for your research: over $100 \mathrm{M}$ website views per year

At $\mathrm{BMC}$, research is always in progress.

Learn more biomedcentral.com/submissions 